MICROSCOPICAL AND CHEMICAL OBSERVATIONS ON A CASE OF SCLEREMA NEONATORUM. ${ }^{1}$

Bv GEORGE CARPENTER, M.D LOND., M.R.C.P. LOND., PHXSICIAN TO THE NORTH-EASTERN HOSPITAL FOR CHILDREN AND GEMBRE CORRESPONDANT DE LA SOCIÉTÉ DE PÉDIATRIE DE PARIS; AND

SHEFFIELD NEAVE, B.A. OxON., M.R.C.P. LOND., ASSISTANT PHYSICIAN TO THE NORTH-EASTERN HOSPITAL FOR CHILDREN.

ThIs disease is not often met with, and less often in Fngland than on the continent. Its favourite localities appear to be in Italy and France. It has been confounded in text-books with oedema neonatorum but it is quite distinct and there is no difficulty in diagnosing between the two. There are nevertheless two disorders, differing at any rate in degree, which both go under this name. The first, by far the commoner in this country, attacks otherwise healthy children of normal term at birth and is practically confined to the skin and the subjacent structures, usually ending in recovery at about six months; while the second, which is more usually found on the continent, attacks weaklings often of premature birth, and is a severe malady with' serious constitutional symptoms of the alimentary and respira tory systems as well as of the kidney and is very fatal." The case about to be described is of the first-mentioned order.

The patient was admitted to hospital on Dec. 30th, 1905, being six weeks old, well nourished, with normal temperature, and in fact normal in every way except for the induration of the skin on the posterior aspect of the body. The skin so affected was of a pink, purplish appearance and of a less even outline than usual, having some well-marked dimples and rounded bot slight eminences. On applying pressure with the finger and then removing it no pitting occurred, but the colour faded to white and slowly returned as the effect of the finger pressure passed off. When the skin was pinched up between the finger and thumb the underlying tissue being closely adherent appeared when doubled together to zeep the fingers more than one inch apart and gave a sensation as if a layer of indiarubber were adherent to the under surface of the skin. This kind of induration extended all over the back and buttocks, the back of the neck and lower part of the back of the scalp, the back of the arms and deltoid regions, and the back of the thighs. In the lastmentioned region it tapered to a point just above the back of the knee in a very characteristic way. The edges of the indurated areas terminated by gradually thinning. Later these signs extended slowly and to a less degree to the angles of the jaws, the sides of the neck, down the arms nearly to the wrist, and there were islets formed all over the abdomen and chest. Pain was never an accompaniment of these indurations. Daring the five months the child has been under observation, althongh the above extensions took place, these signs have cleared up irregularly but continuously. At the time of writing a small triangular patch of induration exists between the shoulders with the apex downwards on the spine, but it is not nearly so thick or hard as in the first place. There are a small patch on the right buttock and an islet on the right cheek just below the superior maxilla. The glands are somewhat enlarged and shotty in the posterior triangle of the neck and in the groin and the spleen reaches one finger's breadth below the ribs. Throughout there was nothing distinctive taking place in respect of the temperature. A blood count was made but gave nothing very definite-viz., poly. morphs, 34; lymphocytes, $57 \cdot 5$; large mononuclears, 0.6 myelocytes, $0 \cdot 5$; and eosinophiles, 2 ; total, 100 ; erythrocytes, 4,212,000; and leucocytes, 22,500. The child has during her stay in the hospital thrived very satisfactorily and the skin has cleared up as described under massage, together with, first, thyroid and then thymus extract given internally. The thyroid was first given for a month when some improvement was made. Thymus was then given, beginning with a small dose and being raised to The ease was exhibited at the Society for the Study of Disease in
Children on Jan. 19th, 1906, and the observations herein recorded were Children on Jan. 19th, 1906

2 DE. A. M. Gray, the resident medical officer, bas searched the record of the North-Eastern Hospital for Children for the past ten years an could find no mention of a case similar to the one about to be reported during that period of time.
30 grains per diem, though subsequently reduced to half that amount. During this last treatment progress appeared to be much hastened.

A small piece of skin and subcutaneous tissue down to the muscle was excised by Mr. J. P. Lockhart Mummery from the back of the thigh for microscopical examination. Macro scopically, the fat and superficial fascia appeared to be perhaps thicker than usual but only slightly. The fat, however, was certainly whiter and in larger globules than usual and was much harder to the touch. Nothing further abnormal was, however, detected under the microscope, a control examination being made at the same time of a similar specimen of healthy skin from another child of the same age. The serous infiltration and increase of connective tissue mentioned in some cases were certainly absent and in this way this case agrees with that of Northrup mentioned by Holt.

The fat was submitted to Professor J. Addyman Gardner, M.A., F.I.C., for examination. He reported as follows :-

I am afraid my investigations do not throw much ljght on the case There were two difficulties which it was impossible to get over: (1) the small quantity of the sample, and (2) the fact that it was probably some. what altered by the prolonged soaking in the formalin fluid. The dry specimen contained only 58 per cent. of fat, the rest being ordinary tissue matter, as far as could be determined in the dried residue after extraction, and this appears to agree with your microscopical report. The saponification equivalent was 205 . The specimen also contained unsaturated fat - e.g., olein-but it was too small to permit of a quantitative estimation. The values usually given for the saponitication tative estimation. The values usually given for the saponification equivalents of the various pure fats are : tripalmitin 209, tristearin 189 , triolein 19 , horse fat $190^{\circ} 4$. One might conclude from this that the specimen was particularly rich in palmitin. In the hope of throwing some light on the matter I examined the saponification equi-
valents of specimens of human fat cut from various parts of the body valents of specimens of human fat cut from

I they showed very considerable variaion. 1 thought at first that the specimen of fat and the acids from it seemed more solid than is usual in human fat, but my examination of the specimen mentioned scarcely bears this out.

On the whole, I am inclined to doubt whether the fat in the sample was in any way abnormal and think that the cause of the trouble mus
be sought in the associated matter.

It is thus obvious that the pathology of the disease is very obscure and it is hoped to call attention to the malady by the publication of this case, so that the work done here, although so negative, may be of some use to others as a starting-point for further investigation when new cases are obtainable.

\section{A CASE OF ACTINOMYCOSIS.}

PRIMARY ABSCESS OF THE LEFT LUNG EXHIBITING SPONTANEOUS CURE ; METASTATIC MANIFESTATION IN. THE PELVIS DECLARING ITSELF AFTER A YEAR'S LATENCY WITH ABSCESS FORMATION AND SLOW SPONTANEOUS CURE.

\section{By EDGAR TREVITHICK, M.D. CANTAB.}

THIs illness occurred in a boy, aged 16 years, and has afforded a good example of a prolonged encounter between a living parasitic fungus on the one hand and human tissues on the other. If, as in this case, there now seems good reason to hope the tissues have ultimately succeeded in permanently stamping out the invasion they alone must be credited with the honours of the victory, for I have not been able to satisfy myself that any of the numerous artificial remedies that have been used bave rendered any real assistance towards the patient's recovery.

There have been many points of interest observable in the course of this case of actinomycosis. It has illustrated in a marked degree the beneficent capabilities of rapid deposition of solid inflammatory exudation and has demonstrated with what great rapidity such exudation can be re-absorbed when its presence is no longer of service. It exemplifies the fact that a parasite may exist somewhere in the body for many months without showing any obvious signs of its whereabcuts and that it may, after long periods of latency, declare its presence by stimulating violent and extensive tissue resentment.

One is tempted to suspict that during the long interval that elapsed in this case between the obsolescence of the original pulmonary lesion and the subsequent breaking-out of the secondary manifestation in the pelvis, obscure internal evolutions of some sort may have been taking place without giving rise to any gross manifestations. The condition of the patient's blood rather favoured such a view. For at the very outset of the second attack there was already 
marked leucocytosis and in addition great excess of extracellular bodies. And it is interesting to wonder along what path the parasite passed in its slow transit from one part of the body to another. The rapid fluctuations of body weight exhibited by the patient during the illness were very striking and the rapid spontaneous cure of the fæcal fistula that resulted in the course of the contest is also of interest.

History of the pulmonary attack. - When first seen on Oct. 19th, 1903, the boy was very wasted, had marked hectic flush, and complained of shortness of breath. He had been employed in "carrying milk from the farm to the village" and had "caught cold," he thought, three months previously. Even since that time he had been getting thinner and losing strength and just recently he had suffered from troublesome dry cough, loss of appetite, and diarrhoea. There had been no expectoration but his friends " had noticed a very curious odour about his breath." On examination I found evidence of extensive consolidation in the lower lobe of the left lung and I, too, was struck by the curious odour of the breath. On 0ct. 26th the patient began to cough up very large quantities of offensive pus, the odour of which resembled that previously remarked in the breath. With the onset of this copious expectoration the general condition began rapidly to improve. A few days later the physical signs indicated the existence of a cavity about the centre of the lower lobe of the left lung, surrounded by a broad zone of consolidation. By Nor. 13th the cough and expectoration were very much less and the latter was no longer offensive. The boy went to a convalescent home on Nov. 30th, weighing 7 stones 7 pounds, having gained 21 pounds in lody weight in 27 days. And later he went back to his own home in the country as "cured" and was written down as having suffered from "abscess of left lung."

It must be confessed that at this stage of the illness no diagnosis of actinomycosis was made. The characteristic yellow bodies which were so plentiful in the discharges from the subsequent pelvic lesions were not noticed in the sputum. They were not, indeed, either thought of or sought for. But certain observations that were written down at the time, taken together with the study of the subsequent course of the case, make it, I think, certain that this pulmonary abscess was in reality caused by the same organism as later asserted itself in another part of the body.

A note written on Oct. 24th, 1903, describes the sputum as follows: "Very offensive, with singular odour. Shreddy, making films that stain badly and seem to contain fatty material. No tubercle bacilli, but swarming with very fine hair-like streptococci showing curious tendency to interlace into tangles." This was a clumsy description but a sketch I made at the time showing the organism, together with my recollection, makes me certain that the "very fine hair-like streptococcus" was in reality derived from actinomyces and makes it probable that the yellow characteristic bodies, although overlooked, may yet have been present. It is not improbable that ordinary clinical observation is easily capable of overlooking their presence in sputum; indeed, this case has led me to reflect about certain other cases of "pneumonia" that have from time to time presented puzzling features and yielded puzzling sputa. I suspect that even in hospital practice the term "pneumonia" as sometimes used is more convenient than scientific.

History of the secondary attack.-After about a year's "perfectly good health" the boy came back complaining of pain in his left flank and exhibiting a very hard craggy lump firmly attached to the brim of the pelvis. From Oct. 26th, 1904, to Sept. 28th, 1905, he was ill in bed and during this year he passed through many vicissitudes of illness, being more than once seemingly at death's door. The body weight in September, 1904, had been 8 stones 2 pounds and this gradually decreased until on April 3rd, 1905, it was 6 stones 4 pounds. At this latter date there was very extensive involvement of the lower part of the abdomen. The infested areas were obstinately and lavishly circum. scribed by very extensive barriers of solid inflammatory exudation, which eventually reached as high as the level of the umbilicus. This abdominal contest was accompanied by irregular and sometimes very high pyrexia and led to the formation of two separate intra-peritoneal abscesses, one of which eventually communicated with the large intestine. There was considerable enlargement of the spleen and the patient's troubles were much aggravated by pressure on nerves and bedsores. About this time it seemed as if recovery was very unlikely. In the end, however, the tissues, as had been the case in the original pulmonary attack, were victorious. On Oct. 2nd, 1905, the body weight had risen to 8 stones 12 pounds. The fæcal fistula had healed spontaneously. The discharge from the two abdominal issues was very greatly reduced and the intra-abdominal buttresses of seemingly solid tissue had all but disappeared. Since Nov. 1st, 1905, the patient had been at work as a baker and in June, 1906, when I saw him, he reported himself and looked in excellent health.

On the subject of treatment I have nothing much to say. The initial manifestation in the lung subsided and healed spontaneously. During the long activity of the subsequent pelvic manifestations many lines of treatment were tried. I was induced to give a long trial to the $x$ rays. I thought their application increased the vascularity of the tissue in the neighbourhood of the issues. Iodide of potassium seemed to me to have no effect.

Bacteriological considerations. - The yellowish bodies characteristic of actinomycosis were abundant for several months in the purulent discharge obtained from the intraabdominal lesions. They were examined by several pathologists who all agreed as to their nature. When one of these bodies, after having been cleansed in sterile salt solution, was incubated in broth a very copious yellowish deposit always formed round it at the bottom of the tube in the course of a few days. And microscopically this deposit, in addition to containing masses of finely divided parts, was always rich in elongated hair-like filaments. Three different observers failed to obtain cultures from it on the surface of solid media. It was injected subcutaneously in rabbits but failed to produce actinomycosis.

I took a good deal of interest in examining the discharges from these lesions. There are observable among the pus cells irregularly shaped interlacements of very delicate filaments, containing in their interstices aggregations of minute bodies irregularly rectangular in sbape. There were also present considerable numbers of the characteristic yellow bodies already mentioned as being visible to the naked eye. These latter seemed on examination to consist of a yellowish amorphous central core, an intermediate interlacement of filaments and a peripheral dressing of club-like bodies. It does not seem very difficult, I think, to imagine the fila. mentous interlacements blossoming out into full-blown characteristic bodies. This imagination was strengthened by observing sections of young colonies of aspergillus glaucus and noting the relationship between the strongly eosinophile and charmingly graceful fruit-heads and the basophile mycelium from which they spring.

Cheltenhan.

\section{Clintial ahtedes:}

\section{MEDICAL, SURGICAL, OBSTETRICAL, AND THERAPEUTICAL.}

\section{A CASE OF SCHÖNLEIN'S PURPURA.}

By Edward C. B. Ibotson, M.B. Lond.

I WAS summoned in the evening of June 11th last to see a boy, aged two years, as something unusual had been noticed in the state of his penis. I found a tight and much swollen prepuce in the condition of phimosis. His mother attributed this to a fall. I also observed that there were some large purple spots on the left thigh. I punctured the cedematous prepuce, squeezed out some of the serum, and ordered lead lotion to be applied frequently. His temperature was normal. On the next day (June 12th) there was still some phimosis, so the lead lotion was continued. The boy's temperature was now $100^{\circ} \mathrm{F}$. and there was a copious purpuric eruption on the legs and arms. The parents were naturally alarmed, fearing some malignant infectious fever. I was, however, able to reassure them, pointing out that there were no signs of variola, measles, or scarlet fever. I also said that in my opinion the disease was either purpura or scurvy and 1 ordered lime-juice well sweetened to be freely given. On the following day there was some urticaria and in the centre of some of the wheals there was purpura. The purpura was strictly confined to the extrenaities-namely,

$$
\text { c } 3
$$

